\title{
Australia Awards Global Tracer Facility: Case Study Interview Guides
}

This document contains the guiding questions used by the Australia Awards Global Tracer Facility (GTF) in its case studies.

The purpose of the GTF is to enable the Department of Foreign Affairs and Trade (DFAT) to assess the long term development contributions and public diplomacy outcomes of Australia's investment in Australia Awards. The GTF is designed to provide a strong evidence base to inform DFAT's management of the Australia Awards.

Case studies are one of two research instruments or methodologies used by the GTF (the other being a Global Tracer Survey). The qualitative method that the case studies follow is designed with a purpose to investigate the detail of development or public diplomacy contributions identified in the Global Tracer Survey that are of interest to the Australian Government or the Australia Awards. All data collection by the GTF is based around a focus on the Australia Awards Long-Term Outcomes.

Each Case Study has a specific focus population. This focus is often based on a country, a cohort (based on years since return from award) and a sector or field of study. Interviews with at least six alumni who fit this cohort form the central element of each Case Study. In order to triangulate responses from alumni and develop a rich contextual background for the analysis, interviews are also undertaken with a range of stakeholders (where possible in-country). Stakeholders include: employers and colleagues of alumni, partner-country Government representatives, staff in DFAT Posts with responsibility for Australia Awards and with portfolio interest in the particular field or sector of focus in the Case Study, Managing Contractors responsible for the Australia Awards in the focus country, alumni association leaders, and/or host institutions/organisations in the case where alumni of fellowships are included.

The guiding questions for interviewing each of these different groups are included in this document. The focus of GTF data collection are on the long-term outcomes of the Australia Awards and as such, the majority of questions aim to explore factors relating to these outcomes. These questions are used as a guide for researchers undertaking the case studies, and as such, in application are not necessarily delivered 'word-for-word' in the interviews. Furthermore, in some case studies conducted by the GTF, a different approach to the one described in the paragraph above is used. In these cases the interview guides are adapted to suit the context and objectives of the case study.

Other researchers are welcome to use or adapt these instruments. However, we request that in doing so the Australia Awards Global Tracer Facility is acknowledged in any reports developed using these instruments. 


\section{Alumni (scholarships)}

Purpose of AAGTF and research: The overall purpose of the Australia Awards Global Tracer Facility (the Facility) is to enable the Australian Department of Foreign Affairs and Trade (DFAT) to assess the development contributions and publicleconomic diplomacy outcomes of Australia's investment in Australia Awards.

Focus of this Case Study: This Case Study in [country, focus years, focus sector]

Consent Form: Please take the time to read through this form regarding your privacy rights and consent. You can withdraw at any time. Contact numbers are also provided should you have any questions following this. Please let us know when you are happy to proceed and to be recorded. You can sign the consent form following the interview if you are happy with the interview.

Do you have any questions for us before we begin?

- Could you please tell us your name, your current position and organisation, and the qualification you completed as part of your Australia Awards scholarship?

1. Can you please tell us why you applied for the scholarship? What was your motivation?

a. Were there any things that made it difficult for you to accept a scholarship and come to Australia?

b. Had you been overseas before?

2. Can you tell us about your time in Australia and experience as a student, we're interested in both:
a. your academic experiences; and
b. your social, 'life' experiences.

3. We are interested in any ongoing friendships and professional connections you made while on award. Can you provide any examples in relation to:
a. Other students: Australian and international?
b. Lecturers/tutors/supervisors at your Australian university?
c. Professional connections with other Australian organisations or businesses?

4. Having completed a qualification in Australia, what do you think about the quality of your course?

5. Can you tell us about your experience when you returned after your scholarship: i.e. reintegration, returning to work or finding a job, returning to your family/friends?
a. What aspects of your return did you find easy?
b. What aspects of your return did you find hard? [probe on what could be done to reduce challenges]

6. How has your career progressed since you returned home? 
7. Thinking about your work since completing your scholarship, have you been able to apply the skills and knowledge gained in Australia?

a. Can you provide example/s?

8. Have you been able to share those new skills and knowledge with others in your work or community?

a. Can you provide example/s?

9. What impact has this scholarship had on your career, and life?

10. If you did not get this scholarship opportunity, what other options were available to you?

11. Are you currently or have been a member of an alumni association?

a. If yes, what was the name of the association? And what sort of activities or services do you get from your membership?

b. If not a member of an association, why not?

c. What should alumni associations do for alumni?

12. How does your career progression compare to your peers who have not studied overseas?

13. From living and studying in a different country, were your views of equality and social inclusion changed?

14. Can you describe an achievement that you are most proud of, in your work or community?

That covers our questions today, is there anything you would like to add?

Follow-ups: If required, CV/Bio, and photograph. 


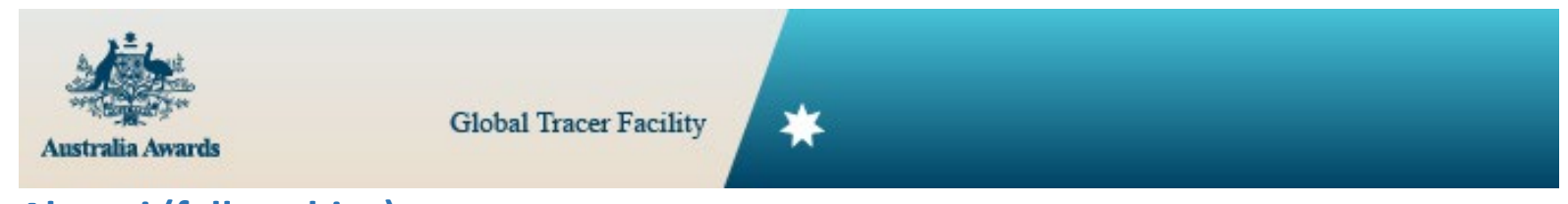

\section{Alumni (fellowships)}

\section{Interview Guide}

Purpose of AAGTF and research: The overall purpose of the Australia Awards Global Tracer Facility (the Facility) is to enable the Australian Department of Foreign Affairs and Trade (DFAT) to assess the development contributions and publicleconomic diplomacy outcomes of Australia's investment in Australia Awards.

Focus of this Case Study: This Case Study in [country, focus years, focus sector]

Consent Form: Please take the time to read through this form regarding your privacy rights and consent. You can withdraw at any time. Contact numbers are also provided should you have any questions following this. Please let us know when you are happy to proceed and to be recorded. You can sign the consent form following the interview if you are happy with the interview.

Do you have any questions for us before we begin?

- Could you please tell us your name, your current position and organisation, and the program you participated in as part of your Australia Awards fellowship?

1. Can you please tell us how the opportunity for the fellowship came about? How were you involved? What was your motivation?
a. Were there any things that made it difficult for you to participate in the fellowship and come to Australia?
b. Had you been overseas before?

2. Can you tell us about your time in Australia and experience during your fellowship:
a. how long you were in Australia
b. your academic experiences; and
c. your social, 'life' experiences.

3. We are interested in any ongoing friendships or professional connections you made while on award. Can you provide any examples in relation to:
a. Other students: Australian and international?
b. Your host organisation or institution?
c. Professional connections with other Australian organisations or businesses?

4. Having completed a fellowship in Australia, what do you think about the quality of your fellowship program?

5. Can you tell us about your experience when you returned after your fellowship: i.e. did you have tasks relating to the program to complete at home? Etc.

a. What aspects of your return did you find easy? 
b. What aspects of your return did you find hard? [probe on what could be done to reduce challenges]

6. Thinking about your work since your fellowship, have you been able to apply the skills and knowledge gained in Australia?

a. Can you provide example/s?

7. Have you been able to share those new skills and knowledge with others in your work or community?

a. Can you provide example/s?

8. What impact has this scholarship had on your career, and life?

9. Are you currently or have been a member of an alumni association?

a. If yes, what was the name of the association? And what sort of activities or services do you get from your membership?

b. If not a member of an association, why not?

c. What should alumni associations do for alumni?

10. 1How does your career progression compare to your peers who have not studied overseas?

11. From your fellowship experience in Australia, were your views of equality and social inclusion changed?

12. Can you describe an achievement that you are most proud of, in your work or community?

That covers our questions today, is there anything you would like to add?

Follow-ups: If required: CV/Bio, and photograph. 


\section{Employers \& Colleagues}

Interview Guide: regarding an individual alumni

Purpose of AAGTF and research: The overall purpose of the Australia Awards Global Tracer Facility (the Facility) is to enable the Australian Department of Foreign Affairs and Trade (DFAT) to assess the development contributions and publicleconomic diplomacy outcomes of Australia's investment in Australia Awards.

Focus of this Case Study: This Case Study in [country, focus years, focus sector]

Consent Form: Please take the time to read through this form regarding your privacy rights and consent. You can withdraw at any time. Contact numbers are also provided should you have any questions following this. Please let us know when you are happy to proceed and to be recorded. You can sign the consent form following the interview if you are happy with the interview.

Do you have any questions for us before we begin?

- Could you please tell us your name, your role and organisation, and how you know [Alumni]? [Also ask for a business card if available]

1. Can you explain [Alumni's] role and responsibilities in your organisation? Could you provide examples?

2. Do you see [Alumni] using skills and knowledge gained from the scholarship in his/her work?

a. Can you provide any example/s? [probe relating to applying skills and knowledge and sharing skills and knowledge]

3. Has your organisation been able to develop links with Australians or Australian organisations as a result of connections [Alumni] made in Australia while on scholarship?

a. Can you provide any example/s?

4. Broadly, in your view, how did studying in Australia impact [Alumni's] career?

That covers the things we wanted to ask. Anything you would like to add? 


\section{Employers \& Colleagues}

Interview Guide: regarding multiple alumni

Purpose of AAGTF and research: The overall purpose of the Australia Awards Global Tracer Facility (the Facility) is to enable the Australian Department of Foreign Affairs and Trade (DFAT) to assess the development contributions and publicleconomic diplomacy outcomes of Australia's investment in Australia Awards.

Focus of this Case Study: This Case Study in [country, focus years, focus sector]

Consent Form: Please take the time to read through this form regarding your privacy rights and consent. You can withdraw at any time. Contact numbers are also provided should you have any questions following this. Please let us know when you are happy to proceed and to be recorded. You can sign the consent form following the interview if you are happy with the interview.

Do you have any questions for us before we begin?

- Could you please tell us your name, your role and organisation? [Also ask for a business card if available]

1. Can you describe your organisation's experience of/relationship with the Australia Awards?

2. Can you explain the impact the Australia Awards scholarships have on your organisation?
a. How many former scholarship holders do you have working in your organisation?
b. Could you provide example/s of the kind of work alumni are doing?
c. Are alumni sharing the skills and knowledge from their award with others in your organisation? Can you provide example/s?

3. Are there other scholarship programs offered to your organisation (or by your organisation)?

4. Has your organisation been able to develop links with Australians or Australian organisations as a result of connections alumni made in Australia while on scholarship?

a. Can you provide any example/s?

That covers the things we wanted to ask. Anything you would like to add? 


\section{Government Stakeholders}

\section{Interview Guide}

Purpose of AAGTF and research: The overall purpose of the Australia Awards Global Tracer Facility (the Facility) is to enable the Australian Department of Foreign Affairs and Trade (DFAT) to assess the development contributions and publicleconomic diplomacy outcomes of Australia's investment in Australia Awards.

Focus of this Case Study: This Case Study in [country, focus years, focus sector]

Consent Form: Please take the time to read through this form regarding your privacy rights and consent. You can withdraw at any time. Contact numbers are also provided should you have any questions following this. Please let us know when you are happy to proceed and to be recorded. You can sign the consent form following the interview if you are happy with the interview.

Do you have any questions for us before we begin?

- Could you please tell us your name, your role and the department you work in?

1. What is your role in relation to the Australia Awards program?

2. How does Australia Awards fit in the human capital development plans of your country?

a. How do you work with the Australian High Commission to achieve alignment of your priorities with those of the Australia Awards?

b. Are there other scholarship programs available to people from your country?

i. How do the Australia Awards 'fit' within this range of other scholarships? [i.e. are there many other offerings, is AA large/small in comparison?]

3. How does the Australia Awards contribute to the bilateral relationship between your country and Australia?

a. Can you provide examples?

4. The Australia Awards is also aiming to help in raising awareness about and promoting opportunities for women and people with disability. Do you think that this awareness raising is being achieved?

a. If so, can you provide example/s?

That covers the things we wanted to ask. Anything you would like to add?

Follow-ups: If required - key documents (development plans, Aus Award \#s, etc) 


\section{DFAT Post}

\section{Interview Guide}

Purpose of AAGTF and research: The overall purpose of the Australia Awards Global Tracer Facility (the Facility) is to enable the Australian Department of Foreign Affairs and Trade (DFAT) to assess the development contributions and publicleconomic diplomacy outcomes of Australia's investment in Australia Awards.

Focus of this Case Study: This Case Study in [country, focus years, focus sector]

Consent Form: Please take the time to read through this form regarding your privacy rights and consent. You can withdraw at any time. Contact numbers are also provided should you have any questions following this. Please let us know when you are happy to proceed and to be recorded. You can sign the consent form following the interview if you are happy with the interview.

Do you have any questions for us before we begin?

- Could you please tell us your name and your role with the Australia Awards Program?

1. In your own words, what is the purpose of the Australia Awards?

a. Do you think the Australia Awards achieves this purpose in [country]?

2. Based on your experience what would you say are the strengths of the Australia Awards Program?

3. How do you think alumni participation in the Australia Awards Program contributes to the development goals of [country]?

a. What evidence/examples have you seen of this happening?

4. In your opinion, how do you think an alumni's participation in the Australia Awards Program contributes to a positive relationships between [country]and Australia?

a. Can you provide any examples of professional partnerships, diplomatic relationships or other aspects of cooperation with Australia developed by or with alumni?

5. Does [country] have an active Australia Awards alumni association?
a. Is this facilitated and funded by DFAT or you as the MC?
b. What sort of activities or services does the association have?
c. If relevant, what are there barriers to further increasing its usefulness?

6. How do you think the Australia Awards contributes to gender equality and disability inclusiveness in [country]?

7. If you had the power to change things about the Australia Awards what would you make different?

That covers the things we wanted to ask. Anything you would like to add? 
Additional questions for sector-specific portfolio focus:

Can you provide a broad overview of [sector/focus area for CS] in this country, particularly in relation to Australia's interest in this area?

What role does the Australia Awards play in DFAT's work in this area? 


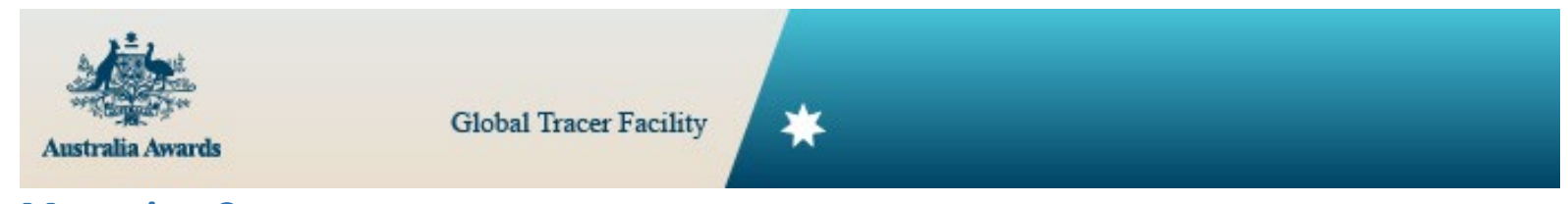

\section{Managing Contractor}

\section{Interview Guide}

Purpose of AAGTF and research: The overall purpose of the Australia Awards Global Tracer Facility (the Facility) is to enable the Australian Department of Foreign Affairs and Trade (DFAT) to assess the development contributions and publicleconomic diplomacy outcomes of Australia's investment in Australia Awards.

Focus of this Case Study: This Case Study in [country, focus years, focus sector]

Consent Form: Please take the time to read through this form regarding your privacy rights and consent. You can withdraw at any time. Contact numbers are also provided should you have any questions following this. Please let us know when you are happy to proceed and to be recorded. You can sign the consent form following the interview if you are happy with the interview.

Do you have any questions for us before we begin?

- Could you please tell us your name and your role with the Australia Awards Program?

1. In your own words, what is the purpose of the Australia Awards?
a. Do you think the Australia Awards achieves this purpose in [country]?

2. Based on your experience what would you say are the strengths of the Australia Awards Program?

3. How do you think alumni participation in the Australia Awards Program contributes to the development goals of [country]?

a. What evidence/examples have you seen of this happening?

4. In your opinion, how do you think an alumni's participation in the Australia Awards Program contributes to a positive relationships between [country]and Australia?

a. Can you provide any examples of professional partnerships, diplomatic relationships or other aspects of cooperation with Australia developed by or with alumni?

5. Does [country] have an active Australia Awards alumni association?
a. Is this facilitated and funded by DFAT or you as the MC?
b. What sort of activities or services does the association have?
c. If relevant, what are there barriers to further increasing its usefulness?

6. How do you think the Australia Awards contributes to gender equality and disability inclusiveness in [country]?

7. If you had the power to change things about the Australia Awards what would you make different?

That covers the things we wanted to ask. Anything you would like to add?

Follow-ups: If required - key documents (development plans, Aus Award \#s, etc) 


\section{Alumni Association}

\section{Interview Guide}

Purpose of AAGTF and research: The overall purpose of the Australia Awards Global Tracer Facility (the Facility) is to enable the Australian Department of Foreign Affairs and Trade (DFAT) to assess the development contributions and publicleconomic diplomacy outcomes of Australia's investment in Australia Awards.

Focus of this Case Study: This Case Study in [country, focus years, focus sector]

Consent Form: Please take the time to read through this form regarding your privacy rights and consent. You can withdraw at any time. Contact numbers are also provided should you have any questions following this. Please let us know when you are happy to proceed and to be recorded. You can sign the consent form following the interview if you are happy with the interview.

Do you have any questions for us before we begin?

- Could you please tell us:

- your name;

- your role with the alumni association;

- the degree and/or scholarship you undertook (incl years); and

- your current job title and organisation?

1. What is the purpose of your alumni association?

2. How many members do you have and what is the profile of your membership (i.e. Aus Awards alum only, broadly what career stage, sectors, gender make-up etc)?

3. What sort of activities opportunities does the association offer?

4. How is the association supported:
a. $\quad$ Financially? [i.e. DFAT/MC funded? Member subscriptions?]
b. In other ways? [i.e. DFAT/MC comms, facilities etc?]

5. What are some of the challenges you have experience in running your alumni association?

6. A key aim of the Australia Awards is to build connections between alumni, Australians and Australian organisations. As such:

a. Do you feel your association is able to play a role in facilitating links with Australia for alumni? If so, how?

b. Do you feel your association has benefited from alumni themselves sharing their connections or networks with Australia? If so, how?

7. What could be done to assist your alumni association to contribute to greater cooperation with Australia and Australian organisations? 
8. As a final overall reflection, what do you think is the most valuable contribution your association provides for alumni?

That covers the things we wanted to ask. Anything you would like to add?

Follow-ups: If required - key documents (Association Charter, membership number info) 


\section{Host Organisation}

\section{Interview Guide}

Purpose of AAGTF and research: The overall purpose of the Australia Awards Global Tracer Facility (the Facility) is to enable the Australian Department of Foreign Affairs and Trade (DFAT) to assess the development contributions and publicleconomic diplomacy outcomes of Australia's investment in Australia Awards.

Focus of this Case Study: This Case Study in [country, focus years, focus sector]

Consent Form: Please take the time to read through this form regarding your privacy rights and consent. You can withdraw at any time. Contact numbers are also provided should you have any questions following this. Please let us know when you are happy to proceed and to be recorded. You can sign the consent form following the interview if you are happy with the interview.

Do you have any questions for us before we begin?

- Could you please tell us your name, your current position and organisation?

1. What was your role and your relationship to the Australia Awards Fellowship [name of fellowship]?

2. Could you please tell us about the fellowship program?
a. Who were the main participants, and how many participated?
b. How long was the program, where was it hosted?
c. What were the key aims of the program?

3. How was the fellowship program designed in order to meet the needs of participants and the goals of the Australia Awards?

a. [If needed]: Was it designed in collaboration with an organisation/ministry from outside Australia?

4. What support was provided to fellows who participated in the program:
a. Prior to the fellowship?
b. During the fellowship?
c. After they had returned home?

5. Were you able to facilitate networking opportunities for fellows to build relevant, ongoing links with Australia and Australians?
a. If yes, can you provide an example?

6. Did the fellowship program assist your organisation/university to build relationships with the organisations/universities/governments of the fellows?
a. If so, can you provide an example? And, is this an ongoing relationship?
b. If not, what are the reasons for this (if known)?

7. Do you think this fellowship achieved its aims?
a. What do you think was its most useful achievement?
b. Were there any unexpected outcomes? 


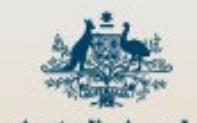

Australia Awards

Global Tracer Facility

c. Were there any challenges experienced?

Do you have anything you would like to add?

Follow-ups: If required, request from Host organisation documentation regarding the program goal, objectives and activities. 